\title{
The impact of certain underlying comorbidities on the risk of developing hospitalised pneumonia in England
}

\author{
J. Campling ${ }^{1 *}$, D. Jones ${ }^{1}$, J. D. Chalmers², Q. Jiang ${ }^{3}$, A. Vyse ${ }^{1}$, H. Madhava ${ }^{1}$, G. Ellsbury ${ }^{1}$ and M. Slack ${ }^{4}$
}

\begin{abstract}
Background: UK specific data on the risk of developing hospitalised CAP for patients with underlying comorbidities is lacking. This study compared the likelihood of hospitalised all-cause community acquired pneumonia (CAP) in patients with certain high-risk comorbidities and a comparator group with no known risk factors for pneumococcal disease.
\end{abstract}

Methods: This retrospective cohort study interrogated data in the Hospital Episodes Statistics (HES) dataset between financial years 2012/13 and 2016/17. In total 3,078,623 patients in England (aged $\geq 18$ years) were linked to their hospitalisation records. This included 2,950,910 individuals with defined risk groups and a comparator group of 127,713 people who had undergone tooth extraction with none of the risk group diagnoses. Risk groups studied were chronic respiratory disease (CRD), chronic heart disease (CHD), chronic liver disease (CLD), chronic kidney disease (CKD), diabetes (DM) and post bone marrow transplant (BMT). The patients were tracked forward from year $0(2012 / 13)$ to Year $3(2016 / 17)$ and all diagnoses of hospitalised CAP were recorded. A Logistic regression model compared odds of developing hospitalised CAP for patients in risk groups compared to healthy controls. The model was simultaneously adjusted for age, sex, strategic heath authority (SHA), index of multiple deprivation (IMD), ethnicity, and comorbidity. To account for differing comorbidity profiles between populations the Charlson Comorbidity Index (CCl) was applied. The model estimated odds ratios (OR) with 95\% confidence intervals of developing hospitalised CAP for each specified clinical risk group.

Results: Patients within all the risk groups studied were more likely to develop hospitalised CAP than patients in the comparator group. The odds ratios varied between underlying conditions ranging from $1.18(95 \% \mathrm{Cl} 1.13,1.23)$ for those with DM to 5.48 (95\% Cl 5.28, 5.70) for those with CRD.

Conclusions: Individuals with any of 6 pre-defined underlying comorbidities are at significantly increased risk of developing hospitalised CAP compared to those with no underlying comorbid condition. Since the likelihood varies by risk group it should be possible to target patients with each of these underlying comorbidities with the most appropriate preventative measures, including immunisations.

Keywords: Pneumonia, Pneumococcus, Hospitalised community acquired pneumonia (CAP), Risk groups, Linkage, Hospital episodes statistics (HES) database, Big data, Prevention

\footnotetext{
* Correspondence: james.campling@pfizer.com

'Pfizer Limited, Walton Oaks, Dorking Road, Tadworth, Surrey KT20 7NS, UK

Full list of author information is available at the end of the article
}

(c) The Author(s). 2019 Open Access This article is distributed under the terms of the Creative Commons Attribution 4.0 International License (http://creativecommons.org/licenses/by/4.0/), which permits unrestricted use, distribution, and reproduction in any medium, provided you give appropriate credit to the original author(s) and the source, provide a link to the Creative Commons license, and indicate if changes were made. The Creative Commons Public Domain Dedication waiver (http://creativecommons.org/publicdomain/zero/1.0/) applies to the data made available in this article, unless otherwise stated. 


\section{Background}

Community acquired pneumonia (CAP) remains a major cause of morbidity and mortality, resulting in a major impact on the UK and European healthcare systems. Across Europe, annual inpatient care for pneumonia accounts for approximately $€ 5.7$ billion of healthcare expenditure [1]. Pneumonia is responsible for more hospital admissions and bed days than any other respiratory disease in the UK [2]. Hospitalised CAP carries a mortality rate of $5-19 \%$ rising to more than $30 \%$ for those admitted to intensive care [3-5] and results in 29,000 deaths per annum. Streptococcus pneumoniae is the most commonly identified cause of CAP; however, the microbiological aetiology is not identified in approximately $50 \%$ of cases $[6,7]$.

There have been a number of studies that have shown patients with a range of underlying comorbidities are at an increased risk of developing IPD [8-12]. Van Hoek et al. used national surveillance data for IPD in England and Wales in combination with Hospital Episodes Statistics (HES) data to demonstrate an increased odds ratio (OR) for hospitalisation and death from IPD in patients with specific risk groups in the UK [12]. The risk varied by underlying comorbidity; with the most important risk factors predicting IPD being chronic liver disease, immunosuppression and chronic respiratory disease. There have to date been a limited number of studies that have examined the risk of developing CAP using healthcare utilisation database records [13, 14]. However, UK specific evidence on the risk of developing hospitalised CAP in key risk groups is lacking. This retrospective pilot study compared the likelihood of being hospitalised with all-cause community acquired pneumonia in patients with pre-specified high-risk comorbidities and a comparator group with no known risk factors for CAP.

\section{Methods}

This retrospective cohort study interrogated data contained within the Hospital Episodes Statistics (HES) dataset between financial years 2012/13 and 2015/16 [15]. 2012/13 will now be referred to as Year 0, 2013/14 as Year 1, 2014/15 as Year 2 and $2015 / 16$ as Year 3. HES is a data warehouse containing clinical information of all admissions, bed days, length of admission, outpatient appointments, attendances at Accident and Emergency Departments at National Health Service (NHS) hospitals in England, discharge diagnoses and hospital death. It is a record-based system covering all NHS hospitals in England. These data are collected to allow hospitals to be paid for the care that they deliver. The primary diagnosis and other clinical conditions are specified using the tenth revision of the International Classification of Diseases version 10 (ICD-10) [16].

Data was extracted from the HES database for adults $\geq 18$ yrs. based on the ICD-10 codes identified. Each patient had his or her own unique NHS identifier which ensured patients were not double counted within the analysis. NHS Digital applies a strict statistical disclosure control in accordance with the HES protocol, to all published HES data. This suppresses small numbers to prevent people identifying themselves and others, to ensure patient confidentiality is maintained.

Patients were grouped together according to their underlying comorbidity (i.e. clinical risk group) which was identified by the relevant ICD-10 codes (Table 3 in Appendix). We chose not to stratify by severity of underlying comorbidity in order to simplify the analysis. They were: Bone Marrow Transplant (BMT), Chronic Respiratory Disease, Diabetes Mellitus (DM), Chronic Kidney Disease (CKD), Chronic Heart Disease (CHD) and Chronic Liver Disease (CLD). These risk factors were selected because they are included in the conditions for which pneumococcal polysaccharide vaccine (PPV23) is recommended by the UK Department of Health [17].

The clinical risk group populations were defined by the following criteria:

Inclusion criteria for clinical risk group populations: 1) A risk group diagnosis (Table 3 in Appendix- ICD-10 CODE) in Year 0. 2) $\geq 18$ years at point of risk group diagnosis. 3) No diagnosis of pneumonia (Table 3 in Appendix- ICD-10 CODE) in either the primary or secondary position in Year 0.4 ) No evidence of in-patient death in Year 0. Exclusion criteria for clinical risk group populations: No pneumonia diagnosis in either the primary or secondary position in Year 0 or Year 1, but with pneumonia diagnosis in Year 2 and/or Year 3. Identification of Pneumonia cases: A pneumonia diagnosis (Table 3 in Appendix- ICD-10 CODE) in either the primary or secondary position in Year 1Year 3. Exclusion of Pneumonia cases: Healthcare Acquired Pneumonia (HCAP) excluded if the pneumonia diagnosis was made within $48 \mathrm{~h}$ of the admission) [18].

Each risk cohort was determined independently; therefore, some patients may have been grouped into multiple risk groups. To ensure that all pneumonia presenting in secondary care was captured 
we included records where the relevant ICD-10 codes were in either the primary or secondary position. The ICD-10 codes chosen to identify risk groups reflected the codes used by van Hoek et al. in their study of the impact of underlying comorbidities on invasive pneumococcal disease [12]. The comparator group consisted of healthy individuals admitted to hospital for a tooth extraction procedure in Year 0 (Table 3 in Appendix for list of ICD10 codes). After careful consideration, we chose individuals admitted to hospital for a tooth extraction, who did not have any of the following underlying comorbidities (leukaemia, multiple myeloma, BMT, HIV, sickle cell, asplenic / splenic dysfunction, CHD, CKD, CLD, DM, malignant disease treatment on immunosuppressive chemotherapy or radiotherapy), as the comparator group. This elective procedure was selected as it was not believed to be directly associated with any underlying comorbidity associated with developing hospitalised CAP, but we excluded any individuals within the comparator group who had any comorbid condition associated with an increased risk of developing pneumococcal infection, as defined by the UK Department of Health, for the duration of the study (Year 0 - Year 3) [17].

Individuals were identified and tracked forward from Year 0 to Year 3 and all diagnoses of hospitalised CAP were recorded. All eligible individuals within the clinical risk groups and the comparator group were followed from Year 0 to Year 3. All episodes of hospitalised CAP that occurred from Year 1 to Year 3 in clinical risk group patients and the comparator group were identified. Information on the patients' age, gender, ethnicity, index of multiple deprivation (IMD) and strategic health authority (SHA) was also extracted.

The study design is shown in Fig. 1.

\section{Statistical analysis}

The outcome of interest was the diagnosis of hospitalised CAP. The odds ratio was calculated as odds of developing hospitalised CAP during Year 1 to Year 3 for patients within a risk group comparing to that for a "healthy" comparator cohort with no risk group diagnosis as defined by the UK Department of Health [17].

A logistic regression model was used to compare the odds of developing hospitalised CAP within a risk group vs within the 'healthy' comparator group. The model was simultaneously adjusted with the age, sex, strategic heath authority (SHA), index of multiple deprivation (IMD), ethnicity of patients, and comorbidity. To account for the fact that the comorbidity profile may have differed between the populations the Charlson Comorbidity Index (CCI) was used [19]. The model estimated odds ratios (OR) with 95\% confidence intervals of developing hospitalised CAP for each specified clinical risk group.

\section{Results}

A total of 3,078,623 patient records were distributed into 6 risk groups and the comparator group. The number of patients within each group is shown in Table 1.

The observed number of cases of hospitalised CAP in each clinical risk group and the comparator group who developed hospitalised CAP between Years 0 to Year 3 is shown in Table 1. The largest clinical risk groups identified in the HES database were approximately 1.3 million patients with CHD; the smallest was approximately 6000 BMT patients.

The odds ratio of developing hospitalised CAP for patients in the clinical risk groups compared with hospitalised CAP cases in the patients with no

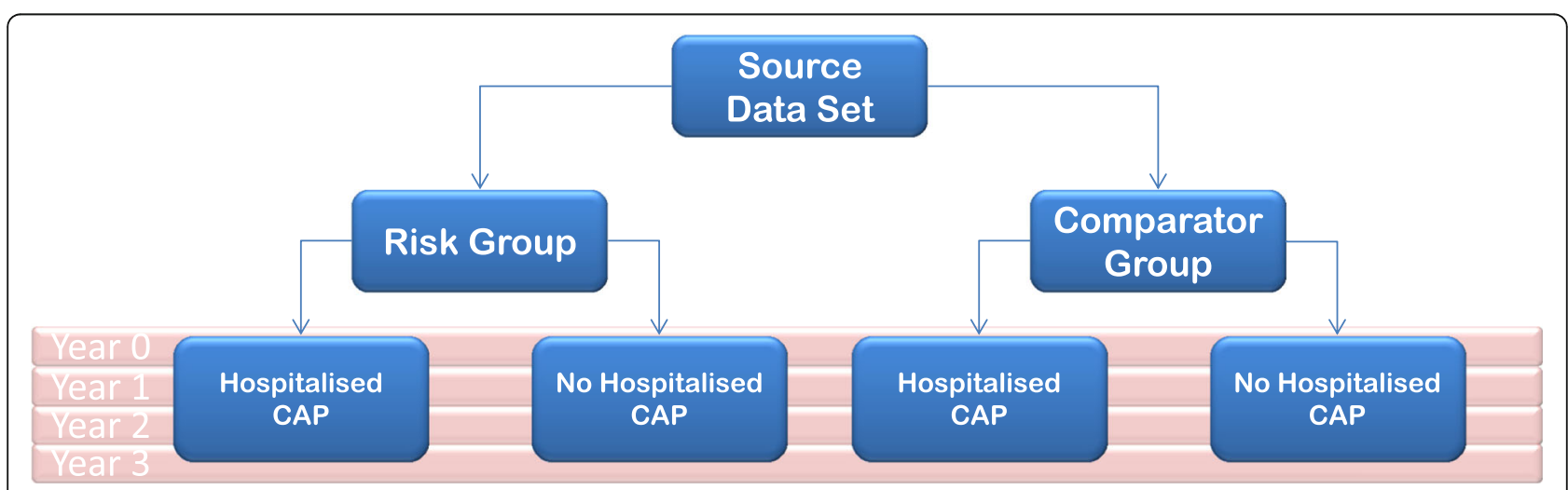

Fig. 1 Study design assessing odds ratio of hospitalised CAP for risk groups compared with "healthy" comparators 
Table 1 Number of patients in risk groups and comparators who did or did not develop CAP

\begin{tabular}{|c|c|c|c|}
\hline Group & $\begin{array}{l}\text { Number of Patients Who Developed } \\
\text { CAP (\%) }\end{array}$ & $\begin{array}{l}\text { Number of Patients Who Did Not Develop } \\
\text { CAP (\%) }\end{array}$ & $\begin{array}{l}\text { Total Number of } \\
\text { Patients }\end{array}$ \\
\hline $\mathrm{CHD}$ & $277,179(21.5 \%)$ & $1,104,335(78.5 \%)$ & $1,291,531$ \\
\hline CKD & $89,144(26.3 \%)$ & $249,384(73.7 \%)$ & 338,541 \\
\hline CLD & 19,516 (19.9\%) & $78,798(80.1 \%)$ & 98,317 \\
\hline CRD & $156,899(33.7 \%)$ & $309,071(66.3 \%)$ & 465,983 \\
\hline DM & $12,072(16.1 \%)$ & $629,303(83.7 \%)$ & 750,379 \\
\hline BMT & $1627(26.4 \%)$ & 4532 (73.6\%) & 6159 \\
\hline $\begin{array}{l}\text { Comparator Group (tooth } \\
\text { extraction) }\end{array}$ & $3203(2.5 \%)$ & $124,510(97.5 \%)$ & 127,713 \\
\hline Total & - & - & $3,078,623$ \\
\hline
\end{tabular}

underlying condition are shown in Table 2 and Fig. 2. These odds ratios (as approximations of relative risk) are reported as are unadjusted and adjusted for potential confounders. For example, the approximate unadjusted risk of CAP in the CHD risk group compared to the comparator group is more than 10-fold higher $(\mathrm{OR}=10.62 ; \quad 95 \% \quad \mathrm{CI}:$ 10.25-11.00). After adjusting for both gender and CCI the OR falls to 3.15. The final model included all factors simultaneously (age, gender, CCI, ethnicity, SHA and IMD), patients with $\mathrm{CHD}$ are about twice as likely to present with CAP compared to those without CHD $(\mathrm{OR}=1.87 ; 95 \% \mathrm{CI}=1.80-1.94)$. For all risk groups studied the factor having the largest influence on the odds of developing CAP was the CCI.

Patients within all the risk groups studied were more likely to develop hospitalised CAP than patients in the comparator group. Patients with CRD had the highest likelihood, with an odds ratio of 5.48 (95\% CI 5.28-5.70). The group studied with the second highest odds of developing CAP was post BMT (odds ratio 5.46 (95\% CI 5.05-5.90). These two clinical risk groups had a five-fold increase of developing hospitalised CAP compared to the comparator group. Patients with DM had the lowest odds of developing hospitalised CAP (odds ratio 1.18 (95\% CI $1.13-1.23)$.

\section{Discussion}

This is the first study utilising HES to quantify the increased likelihood of hospitalised CAP among adults with certain underlying comorbidities in England. HES is an administrative database that contains information on all episodes of hospital care in England. Patient notes are reviewed by coding clerks who assign the ICD-10 codes based on diagnoses recorded by the attending physician. Variabilit in both the quality and consistency of the coding is considered likely. HES also does not contain information on laboratory testing so aetiology of each case cannot be

Table 2 Odds Ratio of risk of hospitalised CAP compared to comparators for each potential confounder

\begin{tabular}{|c|c|c|c|c|c|c|c|c|c|c|c|c|}
\hline \multirow[t]{3}{*}{ Confounder } & \multicolumn{12}{|c|}{ Comparison of CAP vs Non CAP (Odds Ratios) } \\
\hline & \multicolumn{2}{|l|}{$\overline{\mathrm{CHD}}$} & \multicolumn{2}{|l|}{ CKD } & \multicolumn{2}{|l|}{ CLD } & \multicolumn{2}{|l|}{ CRD } & \multicolumn{2}{|l|}{ DM } & \multicolumn{2}{|l|}{ BMT } \\
\hline & $\overline{\mathrm{OR}^{\mathrm{a}}}$ & $(95 \% \mathrm{Cl})$ & $\overline{\mathrm{OR}^{\mathrm{a}}}$ & $(95 \% \mathrm{Cl})$ & $\overline{\mathrm{OR}^{a}}$ & $(95 \% \mathrm{Cl})$ & $\overline{\mathrm{OR}^{a}}$ & $(95 \% \mathrm{Cl})$ & $\overline{\mathrm{OR}^{\mathrm{a}}}$ & $(95 \% \mathrm{Cl})$ & $\overline{\mathrm{OR}^{\mathrm{a}}}$ & $(95 \% \mathrm{Cl})$ \\
\hline Overall (unadjusted) & 10.62 & $(10.25,11.00$ & 13.90 & $(13.41,14.40)$ & 9.63 & $(9.27,10.01)$ & 19.73 & $(19.04,20.45)$ & 7.48 & $(7.22,7.75)$ & 13.96 & $(13.06,14.92)$ \\
\hline Gender: Male & 13.57 & $(12.88,14.28)$ & 14.85 & $(14.09,15.65)$ & 10.98 & $(10.37,11.61)$ & 22.62 & $(21.47,23.82)$ & 8.38 & $(7.95,8.82)$ & 14.92 & $(13.43,16.56)$ \\
\hline Female & 8.28 & $(7.89,8.69)$ & 12.81 & $(12.20,13.46)$ & 8.23 & $(7.81,8.67)$ & 16.92 & $(16.11,17.77)$ & 6.53 & $(6.22,6.86)$ & 12.35 & $(11.32,13.47)$ \\
\hline Adjusting for Gender & 10.44 & $(10.08 ; 10.82)$ & 13.74 & $(13.25,14.24)$ & 9.40 & $(9.05,9.77)$ & 19.39 & $(18.71,20.09)$ & 7.34 & $(7.08,7.61)$ & 13.34 & $(12.47,14.26)$ \\
\hline $\begin{array}{l}\text { Adjusting for Gender } \\
\& \text { CCl }\end{array}$ & 3.15 & $(3.03,3.27)$ & 2.18 & $(2.09,2.27)$ & 2.71 & $(2.60,2.82)$ & 5.55 & $(5.34,5.76)$ & 1.02 & $(0.98,1.07)$ & 3.39 & $(3.16,3.64)$ \\
\hline $\begin{array}{l}\text { Adjusting for Gender, } \\
\text { Age \& CCl }\end{array}$ & 1.86 & $(1.79,1.93)$ & 2.20 & $(2.12,2.30)$ & 3.56 & $(3.41,3.72)$ & 5.61 & $(5.40,5.83)$ & 1.18 & $(1.14,1.23)$ & 5.37 & $(4.99,5.79)$ \\
\hline $\begin{array}{l}\text { Adjusting for Gender, } \\
\text { Age, CCl, Ethnicicty, } \\
\text { STHA \& IMD }\end{array}$ & 1.87 & $(1.80,1.94)$ & 2.22 & $(2.13,2.32)$ & 3.43 & $(3.29,3.59)$ & 5.48 & $5.28,5.70)$ & 1.18 & $(1.13,1.23)$ & 5.46 & $(5.05,5.90)$ \\
\hline
\end{tabular}

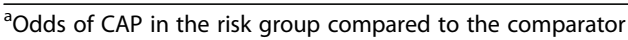


Unadjusted Odds Ratio

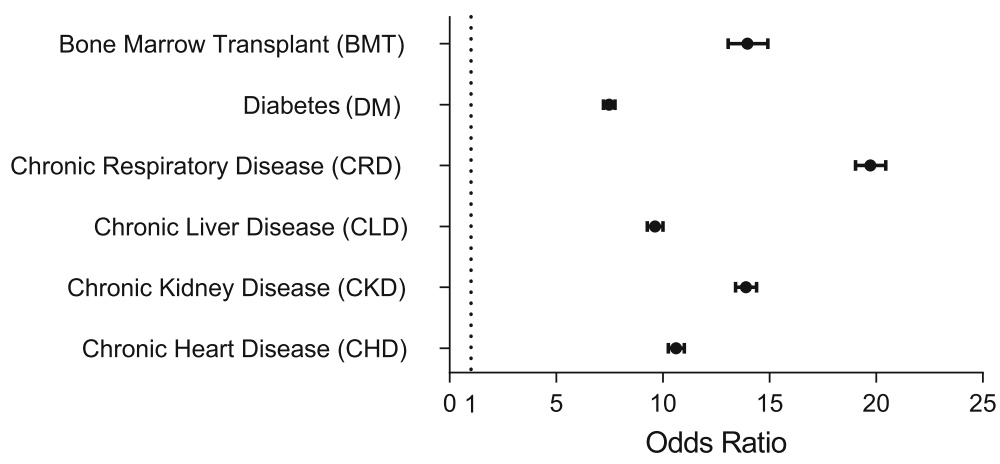

Adjusted Odds Ratio

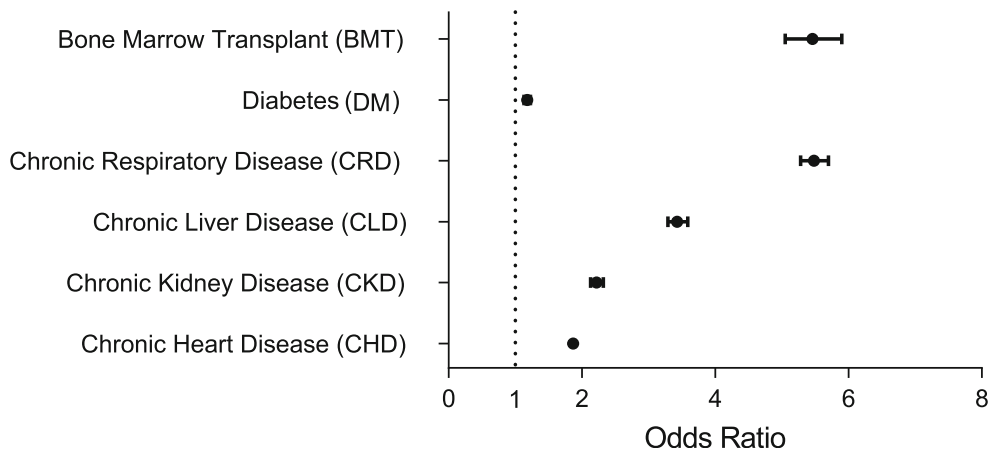

Fig. 2 Odds ratio of risk of developing hospitalised CAP for each clinical risk group

confirmed. Whilst a variety of ICD-10 codes can be used in conjunction with a diagnosis of pneumonia depending on the level of information available, code $\mathrm{J} 18$ is by far the most common of the pneumonia diagnoses and is used when the causative organism is either unknown or unspecified. The most commonly identified causative organism for hospital CAP is $S$. pneumoniae [20, 21]. Despite its limitations HES is frequently used for research in the UK due to its universal coverage, long period of data collection and ability to create nationally representative cohorts that can be followed over time. Whilst there are concerns regarding the accuracy of coding, epidemiological studies using HES are considered informative with HES recently used to study the impact of pneumococcal conjugate vaccine on pneumonia, sepsis and otitis media hospital admissions in England [22-24].

Selecting an appropriate comparator group requires careful consideration. We needed a group of healthy individuals but required them to have had a data entry in the HES database to analyse their health status. We considered people who had attended hospital with broken bones / elective hip \& knee replacement but were concerned about the high level of associated comorbidities. We therefore chose individuals admitted to hospital for a tooth extraction who did not have any of the underlying comorbidities as the comparator group. We believed this procedure was unlikely to be associated with the risk groups under investigation. It has been suggested however that impaired oral hygiene is a risk factor for developing pneumonia therefore the choice of this comparator may have resulted in an underestimation of the impact of the comorbidities studied [25].

For all risk groups studied the factor having the largest influence on the odds of developing CAP was the CCI. Given that the CCI is strongly associated with the other confounding factors that we adjusted for this finding was unsurprising. However, even after adjusting for the CCI the effects of the underlying comorbidities studied remained significant. The impact of gender on the likelihood of developing CAP is well established and has been reported previously [26]. 
The presence of any of the defined underlying risk groups increases the likelihood of a hospital admission for CAP, with the risk varying by condition. The odds ratios varied between 1.18 (95\% CI $1.13,1.23$ ) for DM to 5.48 (95\% CI 5.28, 5.70) for those with CRD, indicating that not only do patients with a risk group diagnosis have an elevated risk of developing hospitalised CAP but also that the underlying diagnosis determines the magnitude of this risk.

Van Hoek and colleagues used the national surveillance programme which monitors IPD in England and linked it with the HES database to determine the odds of developing IPD in patients with specific clinical risk groups [12]. The most important risk factors that predicted IPD were chronic liver disease, immunosuppression and chronic respiratory disease. While van Hoek's results are not directly comparable to our study, the observed patterns in the odds ratios across the risk groups are similar.

Our results are comparable to previous studies within this area in Germany and the United States, which quantify the risk of developing pneumonia in individuals with underlying comorbidities [13, 14]. Shea et al. [14] utilising data from the United States found patients with chronic lung disease had a rate ratio of $6.6(95 \%$ CI $6.6,6.7)$ compared to a healthy population. Patients with chronic heart disease had a rate ratio of 3.8 (95\% CI $3.8,3.80)$. The lower rate ratios derived in our study may reflect a higher threshold for hospitalisation of cases of CAP in the UK, where many cases are treated in primary care.

As with any epidemiological study which relies on diagnostic coding it is possible that, due to the large amount of data within the HES database, some misclassification may have occurred. We therefore chose to interrogate HES from financial year 2012/13 because the reliability of data from this time point improved following changes to the NHS payment process [27].

While we accounted for several relevant confounders, we were unable to adjust for frailty. Frailty, an age-related decline in reserve and function, [28] often coexists with chronic diseases [29]. and will increase the likelihood of hospitalisation with CAP. Since frailty factors are not coded in HES we were unable to determine the contribution of the comorbidity or degree of frailty to hospitalised CAP.

Due to the nature of the coding system it was challenging to differentiate between hospitalised CAP and healthcare- acquired pneumonia (HCAP). We attempted to control for this by excluding cases of pneumonia that developed at least $48 \mathrm{~h}$ post admission (i.e. meeting the definition for HCAP) [30] however this was again dependant on the accuracy with which patients were coded. Patients with a risk group diagnosis may be at an increased risk of developing HCAP compared to those who have not been admitted with an underlying comorbidity. Therefore, it is possible that the presence of HCAP cases within the dataset may have slightly overinflated the reported odds ratios.

We categorised patients based on ICD-10 codes into one of six risk groups. However, many patients will have more than one underlying comorbidity. The risk of developing CAP increases when patients have an increasing number of comorbidities, a phenomenon known as "risk stacking" [14, 31]. There is evidence that immunocompetent adults with two or more underlying risk groups (multimorbidity) have a higher risk of developing pneumococcal disease and patients with three or more at-risk conditions are at similar risk of developing pneumococcal infection as those with immunosuppressive conditions [32]. The role of severity or chronicity of the underlying comorbidity was outside the scope of this study but should be considered by subsequent relevant studies.

We have not accounted for losing patients from the study due to mortality. The HES data warehouse only includes records of patients' contacts with hospitals in England. Mortality data would therefore only reflect death in hospital during an admission, rather than 30day mortality.

\section{Conclusions}

Individuals with any of 6 pre-defined underlying comorbidities are at significantly increased risk of developing hospitalised CAP compared to those with no underlying comorbid condition. The odds ratios varied between underlying conditions ranging from 1.18 (95\% CI 1.13, 1.23) for those with DM to 5.48 (95\% CI $5.28,5.70)$ for those with CRD.

This work begins to address the data gap in terms of defining the burden of CAP in adults with risk factors and compliments work undertaken by van Hoek et al. on IPD. Our study highlights the importance of protecting 'at risk' patients against CAP and the need to consider the role of relevant vaccines in this context, including pneumococcal and influenza vaccine. Since the likelihood varies by risk group it should be possible to target each with the most appropriate preventative measures, including immunisations. 


\section{Appendix}

Table $\mathbf{3}$ List of ICD-10 codes used to identify patients and associated activity

\begin{tabular}{|c|c|c|}
\hline \# & Cohort Name & ICD-10 Codes ${ }^{\mathrm{a}}$ \\
\hline 1. & Pneumonia & $\mathrm{J} 12, \mathrm{~J} 13, \mathrm{~J} 14, \mathrm{~J} 15, \mathrm{J16}, \mathrm{J17}, \mathrm{J18}$ \\
\hline 2. & Chronic respiratory disease & J40, J41, J42, J43, J44, J47, J6, J7, J80, J81, J82, J83, J84, Q30, J31, Q32, Q33, Q34, Q35, Q36, Q37 \\
\hline 3. & Chronic heart disease & $105,106,107,108,109,111,112,113,120,121,122,125,127,128,13,140,141,142,143,144,145,147,148,149,150,151,152$, Q2 \\
\hline 4. & Chronic kidney disease & N00, N01, N02, N03, N04, N05, N07, N08, N11, N12, N14, N15, N16, N18, N19, N25, Q60, Q61 \\
\hline 5. & Chronic liver disease & $\mathrm{K} 70, \mathrm{~K} 71, \mathrm{~K} 72, \mathrm{~K} 73, \mathrm{~K} 74, \mathrm{~K} 75, \mathrm{~K} 76, \mathrm{~K} 77, \mathrm{P} 78.8, \mathrm{Q} 44$ \\
\hline 6. & Diabetes mellitus & E10, E11, E12, E13, E14, E24, G59.0, G63.2, G73.0, G99.0, N08.3, O24, P70.0, P70.1, P70.2 \\
\hline 7. & Post BMT & Z94.8 \\
\hline 8. & Tooth Procedure & $\begin{array}{l}\text { F09: Surgical removal of tooth } \\
\text { F10: Simple extraction of tooth }\end{array}$ \\
\hline
\end{tabular}

${ }^{a}$ ICD-10 codes taken from Rozenbaum et al. [11]

\section{Abbreviations}

BMT: Bone marrow transplant; CAP: Community acquired pneumonia; CCl: Charlson comorbidity index; CHD: Chronic heart disease; Cl: 95\% confidence interval; CKD: Chronic kidney disease; CLD: Chronic liver disease; CRD: Chronic respiratory disease; DM: Diabetes mellitus; HCAP: Healthcare acquired pneumonia; HES: Hospital episode statistics; ICD-10: International Statistical Classification of Diseases and Related Health Problems - 10th revision; NHS: National Health Service; OR: Odds ratio; PPV23: 23-valent plain polysaccharide pneumococcal vaccine

\section{Acknowledgements}

The authors gratefully acknowledge the input from A. P. J Rabe and K. Kishore of Health iQ Ltd. for help with the design of the study, provision of the data and ongoing support.

\section{Authors' contributions}

All authors were involved in draft content development, and in reading and approval of the final manuscript.

\section{Funding}

This research was sponsored by Pfizer. Pfizer provided funding for the following: Hospital Episode Statistics (HES) data processing and analysis by Health iQ Ltd. under an NHS digital re-use agreement and journal publication charges.

\section{Availability of data and materials}

The datasets used and/or analysed for the current article are available from the corresponding author on reasonable request.

\section{Ethics approval and consent to participate}

Not applicable.

\section{Consent for publication}

Not applicable.

\section{Competing interests}

Prof. James Chalmers has received research grant support from AstraZeneca, Pfizer, GlaxoSmithKline, Boehringer-Ingelheim and Bayer Healthcare and has participated in advisory boards or lectures for Griffols, AstraZeneca, Pfizer, Napp, Boehringer-Ingelheim and Bayer Healthcare. He has also received remuneration from Pfizer for services as a member of the Steering Committee for this study. Prof. Mary Slack has received personal fees from GSK, Pfizer, AstraZeneca and Sanofi Pasteur as a speaker at international meetings and as a member of advisory boards (outside the scope of the submitted work). She has also worked as a contractor for Pfizer and received remuneration from Pfizer for services as a member of the Steering Committee for this study. James Campling, Dylan Jones, Qin Jiang, Andrew Vyse, Gillian Ellsbury and Harish Madhava are full-time employees and shareholders of Pfizer; no other conflicts of interest to declare.

\section{Author details}

${ }^{1}$ Pfizer Limited, Walton Oaks, Dorking Road, Tadworth, Surrey KT20 7NS, UK. ${ }^{2}$ University of Dundee, Ninewells Hospital and Medical School, Dundee DD1 9SQ, UK. ${ }^{3}$ Pfizer Vaccines, Collegeville, PA, USA. ${ }^{4}$ School of Medicine, Griffith University, Gold Coast Campus, Gold Coast, Queensland 4222, Australia.

Received: 30 April 2019 Accepted: 12 September 2019

Published online: 11 October 2019

\section{References}

1. Chalmers J, Campling J, Ellsbury G, Hawkey PM, Madhava H, Slack M. Community-acquired pneumonia in the United Kingdom: a call to action. Pneumonia. 2017;9(1):15.

2. Chalmers JD, Campling J, Dicker A, Woodhead M, Madhava H. A systematic review of the burden of vaccine preventable pneumococcal disease in UK adults. BMC Pulm Med. 2016;16(1):77.

3. Barlow G, Nathwani D, Davey P. The CURB65 pneumonia severity score outperforms generic sepsis and early warning scores in predicting mortality in community-acquired pneumonia. Thorax. 2007;62(3):253-9.

4. Lim WS, Baudouin SV, George RC, Hill AT, Jamieson C, Le Jeune I, et al. BTS guidelines for the management of community acquired pneumonia in adults: update 2009. Thorax. 2009:64(Suppl 3):iii1-55.

5. Chalmers JD, Mandal P, Singanayagam A, Akram AR, Choudhury G, Short PM, et al. Severity assessment tools to guide ICU admission in communityacquired pneumonia: systematic review and meta-analysis. Intensive Care Med. 2011:37(9):1409-20.

6. Cilloniz C, Ewig S, Polverino E, Marcos MA, Esquinas C, Gabarrus A, et al. Microbial aetiology of community-acquired pneumonia and its relation to severity. Thorax. 2011;66(4):340-6.

7. Jain S, Self WH, Wunderink RG, Team CES. Community-acquired pneumonia requiring hospitalization. N Engl J Med. 2015;373(24):2382.

8. Wagenvoort GH, Knol MJ, de Melker HE, Vlaminckx BJ, van der Ende A, Rozenbaum $\mathrm{MH}$, et al. Risk and outcomes of invasive pneumococcal disease in adults with underlying conditions in the post-PCV7 era, the Netherlands. Vaccine. 2016:34(3):334-40.

9. Baxter R, Yee A, Aukes L, Snow V, Fireman B, Atkinson B, et al. Risk of underlying chronic medical conditions for invasive pneumococcal disease in adults. Vaccine. 2016;34(36):4293-7.

10. Weycker D, Farkouh RA, Strutton DR, Edelsberg J, Shea KM, Pelton SI. Rates and costs of invasive pneumococcal disease and pneumonia in persons with underlying medical conditions. BMC Health Serv Res. 2016; 16:182.

11. Rozenbaum MH, van Hoek AJ, Fleming D, Trotter CL, Miller E, Edmunds WJ. Vaccination of risk groups in England using the 13 valent pneumococcal conjugate vaccine: economic analysis. BMJ (Clinical research ed). 2012;345: e6879.

12. van Hoek AJ, Andrews N, Waight PA, Stowe J, Gates P, George R, et al. The effect of underlying clinical conditions on the risk of developing invasive pneumococcal disease in England. J Inf Secur. 2012;65(1):17-24. 
13. Pelton SI, Shea KM, Farkouh RA, Strutton DR, Braun S, Jacob C, et al. Rates of pneumonia among children and adults with chronic medical conditions in Germany. BMC Infect Dis. 2015;15:470.

14. Shea KM, Edelsberg J, Weycker D, Farkouh RA, Strutton DR, Pelton SI. Rates of pneumococcal disease in adults with chronic medical conditions. Open Forum Infect Dis. 2014;1(1):ofu024.

15. Kaplan V, Clermont G, Griffin MF, Kasal J, Watson RS, Linde-Zwirble WT, et al. Pneumonia: still the old man's friend? Arch Intern Med. 2003;163(3):317-23.

16. Organisation WH. International statistical classification of diseases and related health problems 10th revision 2010 [8 Nov 2018]. Available from: http://apps.who.int/classifications/icd10/browse/2010/en.

17. England PH. Immunisation against infectious diseases. Pneumococcal: the green book, chapter 252018 [8 Nov 2018]. Available from: https://www.gov. uk/government/publications/pneumococcal-the-green-book-chapter-25.

18. Masterton RG, Galloway A, French G, Street M, Armstrong J, Brown E, et al. Guidelines for the management of hospital-acquired pneumonia in the UK: report of the working party on hospital-acquired pneumonia of the British Society for Antimicrobial Chemotherapy. J Antimicrob Chemother. 2008; 62(1):5-34.

19. Charlson ME, Pompei P, Ales KL, Mackenzie CR. A new method of classifying prognostic comorbidity in longitudinal studies: development and validation. J Chronic Dis. 1987:40(5):373-83.

20. de Roux A, Schmole-Thoma B, Siber GR, Hackell JG, Kuhnke A, Ahlers N, et al. Comparison of pneumococcal conjugate polysaccharide and free polysaccharide vaccines in elderly adults: conjugate vaccine elicits improved antibacterial immune responses and immunological memory. Clin Infect Dis. 2008;46(7):1015-23.

21. Rodrigo C, Bewick T, Sheppard C, Greenwood S, McKeever TM, Trotter CL, et al. Impact of infant 13-valent pneumococcal conjugate vaccine on serotypes in adult pneumonia. Eur Respir J. 2015;45(6):1632-41.

22. Trotter CL, Borrow R, Findlow J, Holland A, Frankland S, Andrews NJ, Miller E. Seroprevalence of antibodies against serogroup $C$ meningococci in England in the postvaccination era. Clin Vaccine Immunol. 2008;15:1694-8.

23. Herbert A, Wijlaars L, Zylbersztejn A, Cromwell D, Hardelid P. Data resource profile: hospital episode statistics admitted patient care (HES APC). Int J Epidemiol. 2017;46(4):1093-i.

24. Thorrington D, Andrews N, Stowe J, Miller E, van Hoek AJ. Elucidating the impact of the pneumococcal conjugate vaccine programme on pneumonia, sepsis and otitis media hospital admissions in England using a composite control. BMC Med. 2018;16(1):13.

25. Azarpazhooh A, Leake JL. Systematic review of the association between respiratory diseases and Oral health. J Periodontol. 2006;77(9):1465-82

26. Millett ER, Quint JK, Smeeth L, Daniel RM, Thomas SL. Incidence of community-acquired lower respiratory tract infections and pneumonia among older adults in the United Kingdom: a population-based study. PLoS One. 2013;8(9):e75131.

27. Health and Social Care Act 2012 (c. 7) Accessed at http://www.legislation. gov.uk/ukpga/2012/7/pdfs/ukpga_20120007_en.pdf.

28. Bergman H, Ferrucci L, Guralnik J, Hogan DB, Hummel S, Karunananthan S, et al. Frailty: an emerging research and clinical paradigm--issues and controversies. J Gerontol A Biol Sci Med Sci. 2007;62(7):731-7.

29. Vaughan L, Corbin AL, Goveas JS. Depression and frailty in later life: a systematic review. Clin Interv Aging. 2015;10:1947-58.

30. American Thoracic Society; Infectious Diseases Society of America. Guidelines for the management of adults with hospital-acquired, ventilatorassociated, and healthcare-associated pneumonia. Am J Respir Crit Care Med. 2005:171(4):388-416.

31. Pelton SI, Shea KM, Weycker D, Farkouh RA, Strutton DR, Edelsberg J. Rethinking risk for pneumococcal disease in adults: the role of risk stacking. Open Forum Infect Dis. 2015;2(1):ofv020.

32. Muhammad RD, Oza-Frank R, Zell E, Link-Gelles R, Narayan KM, Schaffner W, et al. Epidemiology of invasive pneumococcal disease among high-risk adults since the introduction of pneumococcal conjugate vaccine for children. Clin Infect Dis. 2013;56(5):e59-67.

\section{Publisher's Note}

Springer Nature remains neutral with regard to jurisdictional claims in published maps and institutional affiliations.

Ready to submit your research? Choose BMC and benefit from:

- fast, convenient online submission

- thorough peer review by experienced researchers in your field

- rapid publication on acceptance

- support for research data, including large and complex data types

- gold Open Access which fosters wider collaboration and increased citations

- maximum visibility for your research: over $100 \mathrm{M}$ website views per year

At BMC, research is always in progress.

Learn more biomedcentral.com/submissions 